\title{
Study of Antimicrobial Diversity Profile of both Planktonic and Sessile Phenotypes during Chronic Infections of Bovine
}

\author{
Jagyan Narayan Jali ${ }^{1}$, Sangram Singh Naik ${ }^{1 *}$, Rajashree Mishra ${ }^{1}$, \\ Niranjan Soren ${ }^{1}$ and Kautuk Kumar Sardar ${ }^{2}$ \\ ${ }^{1}$ Department of Veterinary Microbiology, College of Veterinary Science and Animal \\ Husbandry, OUAT, Bhubaneswar-(751 003), India \\ ${ }^{2}$ Department of Veterinary Pharmacology and Toxicology, College of Veterinary Science and \\ Animal Husbandry, OUAT, Bhubaneswar-(751 003), India \\ *Corresponding author
}

\section{A B S T R A C T}

\begin{tabular}{|c|}
\hline Keywords \\
\hline $\begin{array}{l}\text { Chronic infection, } \\
\text { Pseudomona aeruginosa, } \\
\text { Biofilm, Substrate, } \\
\text { Antimicrobial resistance }\end{array}$ \\
\hline Article Info \\
\hline $\begin{array}{l}\text { Accepted: } \\
\text { 07 March } 2018 \\
\text { Available Online: } \\
10 \text { April } 2018\end{array}$ \\
\hline
\end{tabular}

In the present study 91 number of samples (which consisted of 55 number of milk samples, 22 number of uterine samples and 14 number of wound swab) were collected from various chronic infections in cows brought to TVCC, C.V. Sc. \& AH for treatment from March 2016 to June 2017. The samples were processed routinely for Pseudomonas aeruginosa isolation as per standard method. A total of 66 numbers $(72 \%)$ of samples were found to be positive for Ps. aeruginosa. Pseudomonas species produced high amount of extra polymeric matrix on CRA Agar. The present study made an alternative approach for antibiotic sensitivity test of chronic bovine infections caused by Pseudomonas. It is revealed that from chronic cases like mastitis, uterine diseases and wound infection the prevalence of Pseudomonas isolates were found to be $61 \%, 24 \%$ and $15 \%$ respectively, which indicated that substrate is necessary for cultivation of Pseudomonas species during antibiotics sensitivity test.

\section{Introduction}

Chronic infection due to Pseudomonas aeruginosa is the major cause of morbidity in animals. Most of the bacteria growing as biofilms during chronic infection as reported by several researchers' biofilms are the major cause of chronic infection. Whereas planktonic pathogens are associated with infection as reported by Anderson and Toole (2008). The clinical impact of biofilms has been intensively studied in the recent years. Biofilms are surface adhered bacterial communities encased in an extracellular matrix composed of DNA, bacterial polysaccharides and proteins which are up to 100 fold more antibiotic resistant than planktonic cultures. Much evidence supports the view that biofilms can survive the antimicrobial treatment during infections. This complex protection relies to a certain extent on general resistance mechanisms including efflux pumps and enzymatic modifications in addition to tolerance derived from biofilm structure. The biofilm matrix reduces exposure of the resident cells to host immune cells and 
antibiotics. Bacterial cells buried within biofilm shave limited access to nutrients, which reduces metabolic activity and subsequently limits the effectiveness of most antibiotics. Taking into the importance of biofilm formation in chronic infections the present study was envisaged to develop a suitable in vivo physiological environment by addition of substrates while conducting antibiotic sensitivity test.

\section{Materials and Methods}

In the present study, 91 no. of samples (55 number of milk samples, 22 number of uterine samples and 14 number of wound swabs) were collected from various chronic infections brought to TVCC for treatment from March 2016 to June 2017. All the samples were processed for antimicrobial sensitivity test as per CLSI and Kirby-Bauer technique (Disk diffusion). However, the effect of various substrates like different sizes of glass beads and conc. of microbial growth both in liquid and solid media used for screening during antibiotic sensitivity test was studied. An attempt was made to study the comparative analysis of minimum inhibitory zone for both acute (planktonic) and chronic (biofilm forming) isolates by addition of bentonite clay and glass beads.

Quarter foremilk samples were collected aseptically as described by HonkanenBuzalski et al., (1995). Chronic mastitic milk samples were collected basing on these physical behaviours of milk. Sub-clinical mastitic milk samples were accepted by doing SCC. Before sampling, the first streams of milk were discarded and teat ends were disinfected with cotton swabs soaked in $70 \%$ alcohol and were allowed to dry. The samples were kept on ice in the laboratory. Swabs were moistened with trypticase soy broth (TSB) before swabbing. Teat canal samples were taken by rotating ultra-fine, sterile, cotton- tipped swabs at an angle of $360^{\circ}$ in the canal. The teat was cleaned, disinfected with chlorhexidine solution and dried with a paper towel before inserting the swab into the canal. Swabs from teat canals were taken prior to milking to control the cleanliness. Disposable latex gloves were used during the sampling. After use all swabs were immediately placed in sterile plastic containers filled with $5 \mathrm{ml}$ of TSB. The containers were cooled and transported to the laboratory within a few hours.

For detection of mastitis, Modified California Mastitis Test (MCMT) score was observed as per Sharma and Rajani (1969). MCMT reagent was prepared as per the formulation of Pandit and Mehta (1969). A number of commercially available synthetic media were used for the study. The media were prepared according to the directions of the manufactures. Along with nutrient broth (NB), the solid media used were Blood Agar (BA), Tryptone soya broth (TSB), Nutrient Agar (NA), Mannitol Salt Agar (MSA). Brain Heart Infusion Agar (BHI), Tryptone Soya Agar (TSA), Mueller Hinton Agar (MHA), McConkey's Lactose Agar (MLA), Bentonite Clay, Congo Red Agar (CRA). All the media used in the study were obtained from HiMedia, Mumbai.

Brain heart infusion broth, Mueller Hinton agar, Blood agar plate (5-10\% sheep blood), EMB agar and MacConkey's agar were employed for isolation of bacteria (Buxton and Fraser, 1977). The Brain heart infusion broth, Mueller Hinton agar, Mac Conkey's agar were prepared by rehydrating dehydrated powdered media of Hi-Media, as per instructions labelled by the manufacturer and required quantities of blood/antibiotics were added subsequently. The plates, slants and broth were kept in incubator at $37^{\circ} \mathrm{C}$ for 24 hour for sterility test. Petriplates with media were dried as described by Cruickshank et al., (1980) 
before streaking. One loopful each of sediment from centrifuged milk was inoculated in BHI broth, streaked on Mueller Hinton agar and Blood agar plates. Single colonies on blood agar plate were examined and their haemolytic pattern was studied. Smears were made from the suspected colonies from blood agar plate, MHA plate as well as from BHI broth culture and stained by Gram's stain (Merchant and packer 1967) and a tentative identification was made. Any isolate appearing diagnostic was stored in pure culture at 4 to $8^{\circ} \mathrm{C}$.

Biofilm formation assay was carried out by Congo red agar plate method. Freeman et al., (1989) method was followed with slight modification. The medium was composed of Tryptone soya agar(Hi-Media, Mumbai) 40 g/l, sucrose $50 \mathrm{~g} / \mathrm{l}$ and Congo red $08 \mathrm{~g} / \mathrm{l}$. Congo red stain was prepared as a concentrated aqueous solution and autoclaved $\left(121^{\circ} \mathrm{C}\right.$ for 15 minutes) separately from the other medium constituents, and was then added when the agar had cooled to $55^{\circ} \mathrm{C}$. Plates of the medium were inoculated and incubated aerobically for 24 hours at $37^{\circ} \mathrm{C}$. A positive result was indicated by black colonies with dry crystalline consistency. Non-slime producers usually remained pink, though occasional darkening at the centre of the colonies was observed and this gave a bulls eye appearance. An indeterminate result was indicated by a darkening of the colonies but with the absence of a dry crystalline colonial morphology. Isolates presenting two tons of black, bright black (BB) and dry opaque black (OB), were classified as biofilm producers, whereas red, pink and bordeaux colonies were classified as negative.

Polysaccharide producing Ps. aeruginosa strains were determined on Congo Red agar plates. Initially the isolates were inoculated in BHI broth incubated at $37{ }^{\circ} \mathrm{C}$ for 16 hours. Then the cultures were streaked into CRA plates and were incubated at 37 degree Celsius for $24 \mathrm{hrs}$ and subsequently kept at room temperatures for 48 to $72 \mathrm{hrs}$. Isolates growing as black color colonies with a dry and crystalline consistency were considered positive for biofilm production and the entire procedure was repeated for three times. All the 66 no. of isolates of Pseudomonas species were tested for minimum zone of inhibition as per the procedure of CLSI (2012). Briefly, colonies of Ps. aeruginosa from, a 24 hour culture grown at $37^{\circ} \mathrm{C}$ on Mueller Hinton agar plates were re-suspended into $5 \mathrm{ml}$ of saline to achieve 0.5 McFarland turbidity. This adjusted inoculum was streaked on MHA plates and sensitivity pattern was determined by disk diffusion testing. Modified broths were prepared by addition of various substrates i.e glass beads. A total of 4 to 5 grams of grounded glass was added to $5 \mathrm{ml}$ of broth during primary isolation of biofilm performing Pseudomonas aeruginosa. Thin glasses around $2 \mathrm{~mm}$ and $4 \mathrm{~mm}$ (measured by slide calliper) were obtained by grinding with pestle $\&$ mortar in to small pieces. The ground glasses were of different coarse edges, hence, round glass beads with a diameter of $4 \mathrm{~mm}$. with fine surfaces were also used in the present study. A comparative analysis was made between the bio film forming growth of Pseudomonas aeruginosa inoculated with three conditions (Fig. 1), i.e. (1) BHI normal broth inoculated with Pseudomonas aeruginosa (2) BHI broth with round glass beads and then inoculated with Pseudomonas aeruginosa and (3) BHI broth with coarse ground glass inoculated with Pseudomonas aeruginosa. Ground glass with various pore diameters were passaged through the strainer of different pore size measuring $2 \mathrm{~mm}, 4 \mathrm{~mm}$, $8 \mathrm{~mm}$ and were graded as gr. 1 to gr.3. The ground glasses were sterilized separately as per grade, and 10 to $12 \mathrm{~g}$. Ground glass grade (gr. 1 to3) were evenly distributed on the surface of the petriplate so that a layer of uniform ground glass was formed on the bottom of the MHA agar plate. 
A total of $10-15$ plates were prepared in the above manner and were inoculated with separately for antibiotic sensitivity test. In the present study, $0.3 \%$ of bentonite clay was added as a substrate to Mueller Hinton agar for development of biofilm producing pseudomonas isolates. In order to compare the surface attached growth i.e. the bio-film growth to its counterpart, a set of control MHA agar plates were also prepared and inoculated with the same condition for antibiotics sensitivity test.

The corresponding antibiotic sensitivity profile was prepared. The cultures containing both fine and coarse glasses were streaked.

Polysaccharide-producing Ps. aeruginosa strains were determined by cultivation on agar plates containing Congo Red. Initially, the bacteria were inoculated in BHI broth and incubated at $37^{\circ} \mathrm{C}$ for $16 \mathrm{~h}$ with agitation. The cultures were then streaked onto CRA plates and incubated at $37^{\circ} \mathrm{C}$ for $24 \mathrm{~h}$ and subsequently kept at room temperature for 48 $\mathrm{h}$ and $72 \mathrm{~h}$. The isolates growing as black colonies with a dry and crystalline consistency were only considered to be slime producers. The assay was repeated three times for each isolate.

\section{Results and Discussion}

Ps. aeruginosa isolates were determined as per the method of Bergy's determinative bacteriology and prevalence rate was interpreted (Table 1 and 2). A total of 14 randomly selected isolates were identified as Pseudomonas aeruginosa by morphological and biochemical tests (Table 3) and were subjected to biofilm production in Congo Red Agar (Fig. 2) as per the method of Helen et al., (2015). The antibiotics sensitivity profile revealed that the zone of inhibition of biofilm producing (addition of glass beads and bentonite clay) Ps. aeruginosa against all the 8 antibiotics was found to be less than that of its planktonic counterparts (Fig. 4 and 5). The degree of resistance of Ps. aeruginosa was minimum four fold increased as compared to without glass bead and bentonite clay inoculated isolates (Table 4 and 5).

Table.1 Prevalence and isolation of Ps. aeruginosa in chronic infection of cows

\begin{tabular}{|c|c|c|c|}
\hline SI No. & Nature of the sample & No. of Isolation & Isolation (\%) \\
\hline 1 & Milk & $55 / 91$ & 61 \\
\hline 2 & Uterine Discharge & $22 / 91$ & 24 \\
\hline 3 & Wound Swab & $14 / 91$ & 15 \\
\hline & Total & $\mathbf{9 1}$ & $\mathbf{1 0 0}$ \\
\hline
\end{tabular}

Table.2 Number of isolates found positive for Ps. aeruginosa

\begin{tabular}{|c|c|c|c|c|}
\hline $\begin{array}{c}\text { Sl. } \\
\text { No. }\end{array}$ & $\begin{array}{c}\text { Nature of sample } \\
\text { collected }\end{array}$ & $\begin{array}{c}\text { Total Number } \\
\text { of Samples } \\
\text { Collected }\end{array}$ & $\begin{array}{c}\text { Number of } \\
\text { Positive } \\
\text { Samples }\end{array}$ & $\begin{array}{c}\text { Percentage of } \\
\text { prevalence }\end{array}$ \\
\hline 1 & Milk & 55 & 32 & 58 \\
\hline 2 & Uterine Discharge & 22 & 22 & 100 \\
\hline 3 & Wound Swab & 14 & 12 & 85 \\
\hline
\end{tabular}


Table.3 Biochemical profile of Pseudomonas aeruginosa

\begin{tabular}{|c|c|c|c|c|}
\hline $\begin{array}{c}\text { SI. } \\
\text { No. }\end{array}$ & $\begin{array}{c}\text { Name of the } \\
\text { biochemical test }\end{array}$ & $\begin{array}{c}\text { No. of } \\
\text { isolates }(+)\end{array}$ & $\begin{array}{c}\text { No. of isolates } \\
(-)\end{array}$ & $\begin{array}{c}\text { No. of isolates } \\
\text { doulbtful }\end{array}$ \\
\hline 1 & Indol & $12 / 18$ & 22 & Nil \\
\hline 2 & NO3 & $12 / 12$ & $9 / 12$ & Nil \\
\hline 3 & Catalase & $12 / 12$ & $4 / 12$ & Nil \\
\hline 4 & Oxidase & $12 / 12$ & $5 / 12$ & Nil \\
\hline 5 & MRVP & $10 / 12$ & Nil & Nil \\
\hline 6 & Gelatin & $12 / 12$ & Nil & Nil \\
\hline 7 & Glucose & Negative & Nil & Nil \\
\hline
\end{tabular}

Table.4 Antibiotic sensitivity profile after addition of glass beads on substrate zone of inhibition

\begin{tabular}{|c|c|c|c|}
\hline $\begin{array}{c}\text { Sl. } \\
\text { No. }\end{array}$ & $\begin{array}{c}\text { Name of the } \\
\text { anti-microbials }\end{array}$ & $\begin{array}{c}\text { Without addition of glass } \\
\text { beads(n=14)(planktonic) }\end{array}$ & $\begin{array}{c}\text { Addition of } \mathbf{4 . 5} \text { gms/5ml of } \\
\text { glass beads in the } \\
\text { broth(n=14) }\end{array}$ \\
\hline 1 & Ciprofloxacin & 24.5 & 21.5 \\
\hline 2 & Piperacillin & 15.8 & 14 \\
\hline 3 & Ceftazidime & 15.5 & 12.5 \\
\hline 4 & Imipenam & 31.3 & 23.5 \\
\hline 5 & Amikacin & 19.5 & 15.6 \\
\hline 6 & Aztreonam & 20 & 18.6 \\
\hline 7 & Ceftriaxone & 15.5 & 12.5 \\
\hline 8 & Meropenem & 30.2 & 20.5 \\
\hline
\end{tabular}

Table.5 Antibiotic sensitivity profile of Ps. aeruginosa by addition of bentonite clay as substrate

\begin{tabular}{|c|c|c|c|}
\hline \multirow{2}{*}{$\begin{array}{c}\text { Sl. } \\
\text { No. }\end{array}$} & $\begin{array}{c}\text { Name of the } \\
\text { anti- microbials }\end{array}$ & $\begin{array}{c}\text { Without addition of } \\
\text { bentonite clay(n=14) } \\
\text { (planktonic) }\end{array}$ & $\begin{array}{c}\text { Addition of o.3\% of bentonite clay } \\
\text { in the broth(n=14) (biofilm } \\
\text { forming) }\end{array}$ \\
\hline 1 & Ciprofloxacin & 26.5 & 18.5 \\
\hline 2 & Piperacillin & 15.5 & 13.8 \\
\hline 3 & Ceftazidime & 16 & 14.5 \\
\hline 4 & Imipenam & 32.2 & 28.6 \\
\hline 5 & Amikacin & 18.8 & 14.9 \\
\hline 6 & Aztreonam & 21 & 19.2 \\
\hline 7 & Ceftriaxone & 14.8 & 11.7 \\
\hline 8 & Meropenem & 31.2 & 22.6 \\
\hline
\end{tabular}


Fig.1 Inoculation of Pseudomonas aeruginosa in normal BHI broth and BHI broth with irregular glass beads and round glass beads

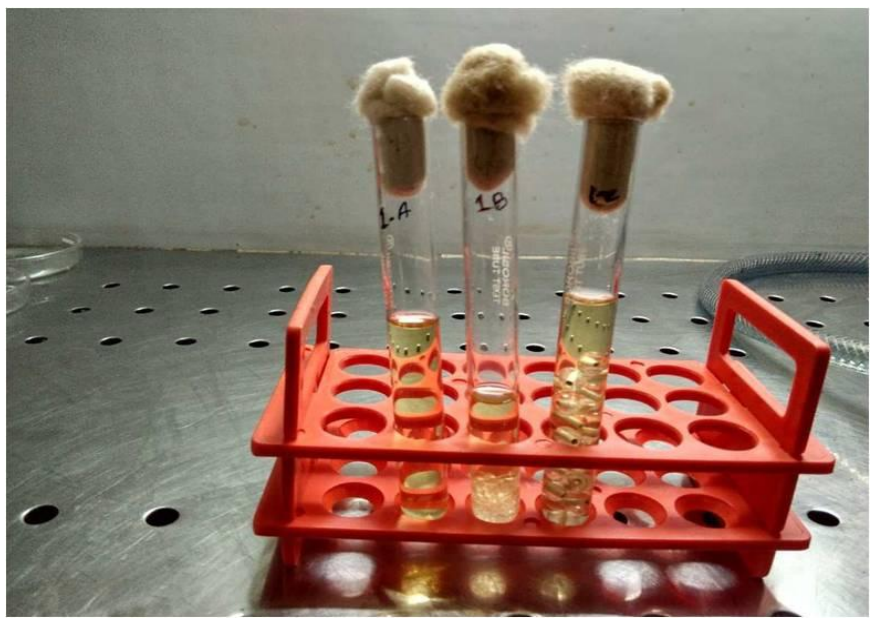

Fig.2 Growth of Pseudomonas isolates on Congo red agar medium

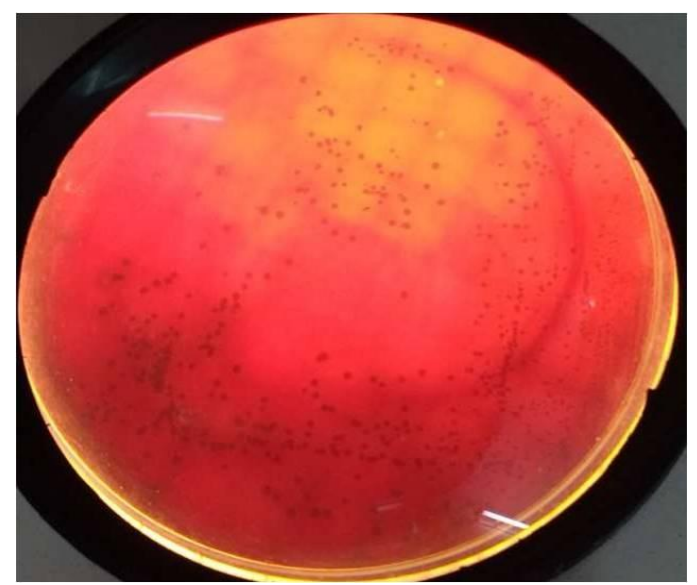

Fig.3 Pigment production of Pseudomonas aeruginosa in normal MHA Agar

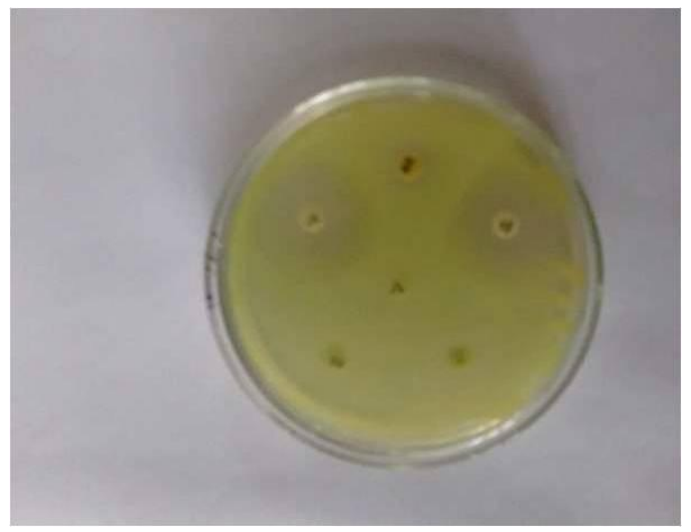


Fig.4 Zone of inhibition of $P$. aeruginosa with addition of ground glass

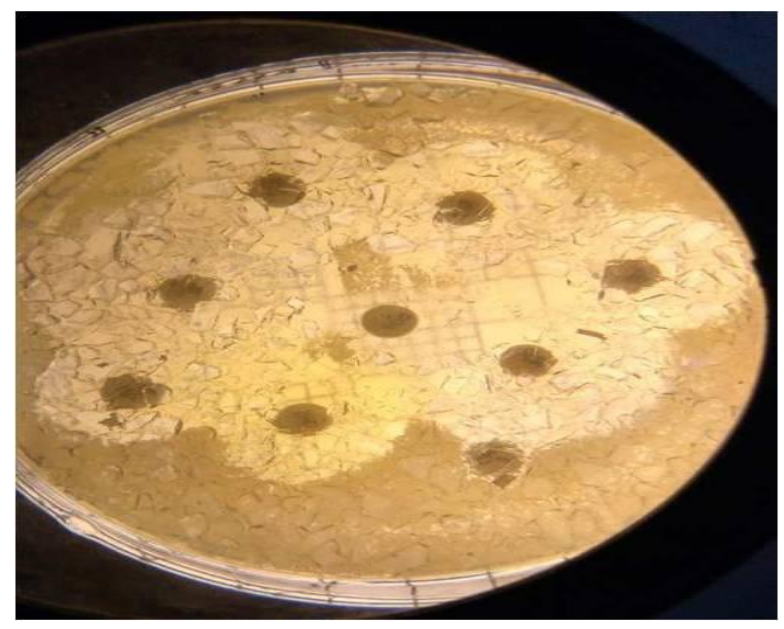

Fig.5 Zone of inhibition of Pseudomonas aeruginosa on MHA agar with substrate as bentonite clay

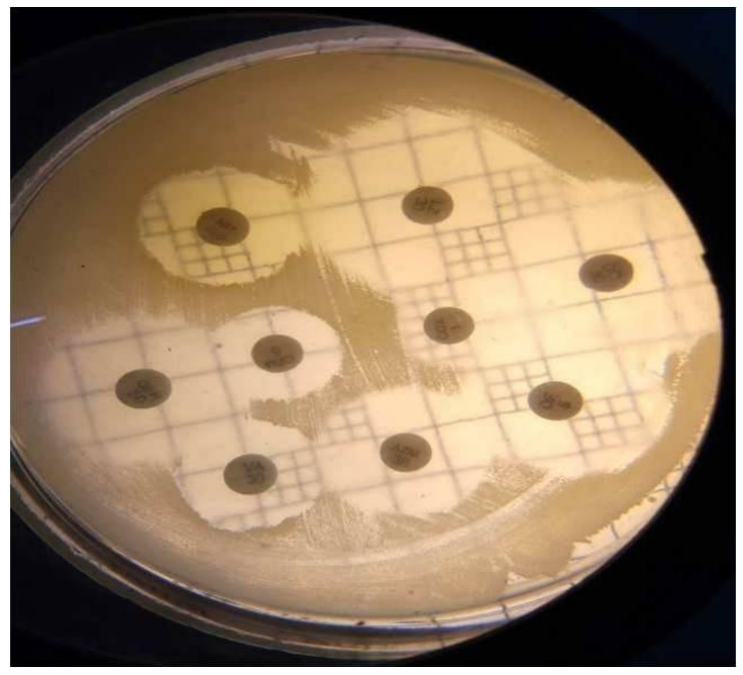

The most widely used method for detection of antibiotics resistance pattern in Pseudomonas aeruginosa is by phenotypic measurement of its growth in presence of antibiotics being tested. These methods can be able to detect rapidly the antimicrobial resistance profile to reduce the cost of antibiotic therapy and effective targeted treatments. But there are limitation and lots of gap between the clinical testing and effective treatments against biofilm forming chronic infections.
The present study focused on changes of sensitivity profile Pseudomonas aeruginosa which causes chronic mastitis in cattle by addition of various substrates in the broth dilution methods. In order to establish the modified method, a great no of trial testing is essential in various physiological conditions. Effect of physical conditions are also need to be analysed taking into consideration of effect of $\mathrm{pH}$, salt conc. and other substrates on zone of inhibitions. 


\section{References}

Anderson GG and Toole GA. 2008. Innate and induced resistance mechanisms of bacterial biofilms, Curr Top Microbiol Immunol., 322:85-105.

Bauer AW, Kirby WM and Sherris JC.1996. Antibiotic susceptibility testing by a standardized single disk method, American Journal of Clinical Pathology, 45: 493- 496

Bergey's Manual of Determinative Bacteriology - Bergey's Manual of Determinative Bacteriology, 1st edn.

Buxton A. and Fraser G.1977.Animal Microbiology, Vol-I, Blackwell Scientific Publications Ltd., Oxford, London

Cruickshank R, Duguid JP, Marmion BP, Swain RHA. 1980. Medical Microbiology; Twelfth Ed. Vol.II, Churchill, Livingstone London

Egbe CA, Omoregie R, Igbarumah IO, Onemu S. 2011. Microbiology of Wound Infections and its Associated Risk Factors among Patients of a Tertiary Hospital in Benin City, Nigeria, JRHS, 11(2): 109-113

Freeman DJ, Falkiner FR, Keane CT.1989. New method for detecting slime production by coagulase negative Staphylococci, J Clin Patho., 42:872874

Helen Treichel. 2015. School of Biochemistry, Genetics and Microbiology, 9 (2): 14.

Honkanen-Buzalski T. 1995. Bovine mastitis in Finland in 1988 and 1995, Gummerus Press, Jyväskylä, Finland, pp.111-114.

Mackie \& Mccartney Practical Medical Microbiology 1996. Publisher: Elsevier; 14 edition

Merchant and Packer. 1967. Gram's staining, the morphology of the isolated bacteria Vol. 2 Systematic Bacteriology

Pandit AV, Mehta ML.1969.Sodium lauryl sulphate as a substitute for CMT (California mastitis reagent) for diagnosis of sub-clinical mastitis in buffaloes; Indian Veterinary Journal, 40:111-119.

Sharma VK, Rajani HB. 1969. California Mastitis Test; Indian Vet J. Sep; 46(9):749-52.

Wilson GS and Miles AA. 1965, International Journal of Systematic and Evolutionary Microbiology p.15.

\section{How to cite this article:}

Jagyan Narayan Jali, Sangram Singh Naik, Rajashree Mishra, Niranjan Soren and Kautuk Kumar Sardar. 2018. Study of Antimicrobial Diversity Profile of both Planktonic and Sessile Phenotypes during Chronic Infections of Bovine. Int.J.Curr.Microbiol.App.Sci. 7(04): 452-459. doi: https://doi.org/10.20546/ijcmas.2018.704.052 